\title{
Inconclusive Diagnosis after Newborn Screening for Cystic Fibrosis
}

\author{
Anne Munck \\ Hopital Necker Enfants-Malades, AP-HP, CF centre, Université Paris Descartes, 75015 Paris, France; \\ anne.munck1@gmail.com; Tel.: +33-60-9372-870
}

Received: 13 February 2020; Accepted: 10 March 2020; Published: 12 March 2020

\begin{abstract}
An unintended consequence of newborn screening for cystic fibrosis $(\mathrm{CF})$ is the identification of infants with a positive screening test but an inconclusive diagnostic testing. These infants are designated as CF transmembrane conductance regulator-related metabolic syndrome (CRMS) in the US and CF screen-positive, inconclusive diagnosis (CFSPID) in Europe. Recently, experts agreed on a unified international definition of CRMS/CFSPID which will improve our knowledge on the epidemiology and outcomes of these infants and optimize comparisons between cohorts. Many of these children will remain free of symptoms, but a number may develop clinical features suggestive of CFTR-related disorder (CFTR-RD) or CF later in life. Clinicians should to be prepared to identify these infants and communicate with parents about this challenging and stressful situation for both healthcare professionals and families. In this review, we present the recent publications on infants designated as CRMS/CFSPID, including the definition, the incidence across Europe, the assessment of the CFTR protein function, the outcomes with the rates of conversion to a final diagnosis of CF and their management.
\end{abstract}

Keywords: cystic fibrosis; CF transmembrane conductance regulator-related metabolic syndrome; CF screen positive; inconclusive diagnosis; newborn screening

\section{Introduction}

Newborn screening (NBS) for cystic fibrosis (CF), when combined with very early multidisciplinary care at CF centers (CFC), is acknowledged as the optimal approach to CF diagnosis, as it maximizes the long-term prognosis and survival of these children [1-3]. However, beyond the goal of NBS and irrespective of the screening protocol used, there is the detection of infants with a positive NBS test and an inconclusive designation [4]. The terminology used for these infants is CF transmembrane conductance regulator-related metabolic syndrome (CRMS) in the US [5] and CF screen-positive, inconclusive diagnosis (CFSPID) in Europe [6]. Many of these children will remain asymptomatic, but later in life, a number of them may develop symptoms suggestive or CFTR-related disorder (CFTR-RD) or CF [7]. The approach to these infants is evolving as clinical experience grows; nevertheless, uncertainty remains challenging for families and caregivers

\section{Inconclusive Diagnosis after Newborn Screening}

\subsection{Definition of CRMS/CFSPID}

For infants with a positive NBS test but an inconclusive diagnosis, a definition has been created using the terminology CRMS in the US since 2009 [5] that is included in the International Statistical Classification of Diseases and Related Health Problems, Ninth Revision medical code (277.9), which is mandatory in the US for healthcare delivery. Recently, in Europe, a Delphi process conducted by the European CF Society (ECFS) Neonatal Screening Working Group (NN WG) identified the need for a 
designation, and the terminology CFSPID was introduced in 2015 [6]. The differences between these two definitions were minor. To optimize comparisons between cohorts and thus improve our knowledge on the epidemiology and outcomes, experts from around the world gathered at a Diagnosis Consensus Conference held in the US, in 2015, and agreed on a unified definition (Table 1) of CRMS/CFSPID [8], with a recently published algorithm for this definition in Figure 1 [9]. This definition incorporates the knowledge on CFTR variants characteristics as "CF causing", "non-CF causing", "varying clinical consequences" or "unknown significance" [10] in the CFTR2 database, which is regularly updated and searchable on the website https://cftr2.org. However, an international survey conducted in 2018 by ECFS NN WG, with support of the Cystic Fibrosis Foundation (CFF) NBS Quality Improvement Group, showed significant confusion in regard to the correct designation of inconclusive diagnosis in six scenarios of infants screening positive. In one-third to half of the respondents, who were either CF doctors or pediatric pulmonologists [9], the diagnosis option was incorrect, thus identifying the need for improved education and communication.

Table 1. Definitions for CF transmembrane conductance regulator-related metabolic syndrome (CRMS) and CF screen-positive, inconclusive diagnosis (CFSPID) and the harmonized definition CRMS/CFSPID.

\begin{tabular}{llll}
\hline & Positive NBS & And & Or \\
\hline $\begin{array}{l}\text { CRMS [5] } \\
\text { US }\end{array}$ & $\begin{array}{l}\text { Asymptomatic infants } \\
\text { with hypertrypsinemia } \\
\text { at birth }\end{array}$ & $\begin{array}{l}\text { Persistently intermediate sweat } \\
\text { chloride levels }{ }^{1} \text { and fewer than } 2 \\
\text { CF-causing CFTR mutations }\end{array}$ & $\begin{array}{l}\text { Sweat chloride concentration } \\
<30 \text { mmol/L and 2 CFTR } \\
\text { mutations with 0 or } 1 \text { known to be } \\
\text { CF-causing }\end{array}$ \\
\hline $\begin{array}{llll}\text { CFSPID [6] } \\
\text { Europe }\end{array}$ & $\begin{array}{l}\text { Asymptomatic infants } \\
\text { with hypertrypsinemia } \\
\text { at birth }\end{array}$ & $\begin{array}{l}\text { 0 or 1 CFTR mutation, plus } \\
\text { intermediate sweat chloride } \\
(30-59 \text { mmol/L) }\end{array}$ & $\begin{array}{l}\text { 2 CFTR mutations, at least } 1 \text { of } \\
\text { which has unclear phenotypic } \\
\text { consequences, plus a normal } \\
\text { sweat chloride (<30 mmol/L) }\end{array}$ \\
\hline CRMS/CFSPID [8] & $\begin{array}{l}\text { Infants with positive } \\
\text { newborn screening test }\end{array}$ & $\begin{array}{l}\text { Sweat chloride }<30 \text { mmol/L and 2 } \\
\text { CFTR mutations with 0 or } 1\end{array}$ & $\begin{array}{l}\text { Sweat chloride 30-59 mmol/L and } \\
\text { CF-causing CFTR mutation } 1 \text { CF-causing CFTR mutation }\end{array}$ \\
\hline
\end{tabular}

${ }^{1}$ Sweat chloride levels: $30-59 \mathrm{mmol} / \mathrm{L}$ if age $<6$ months or $40-59 \mathrm{mmol} / \mathrm{L}$ if age $\geq 6$ months.

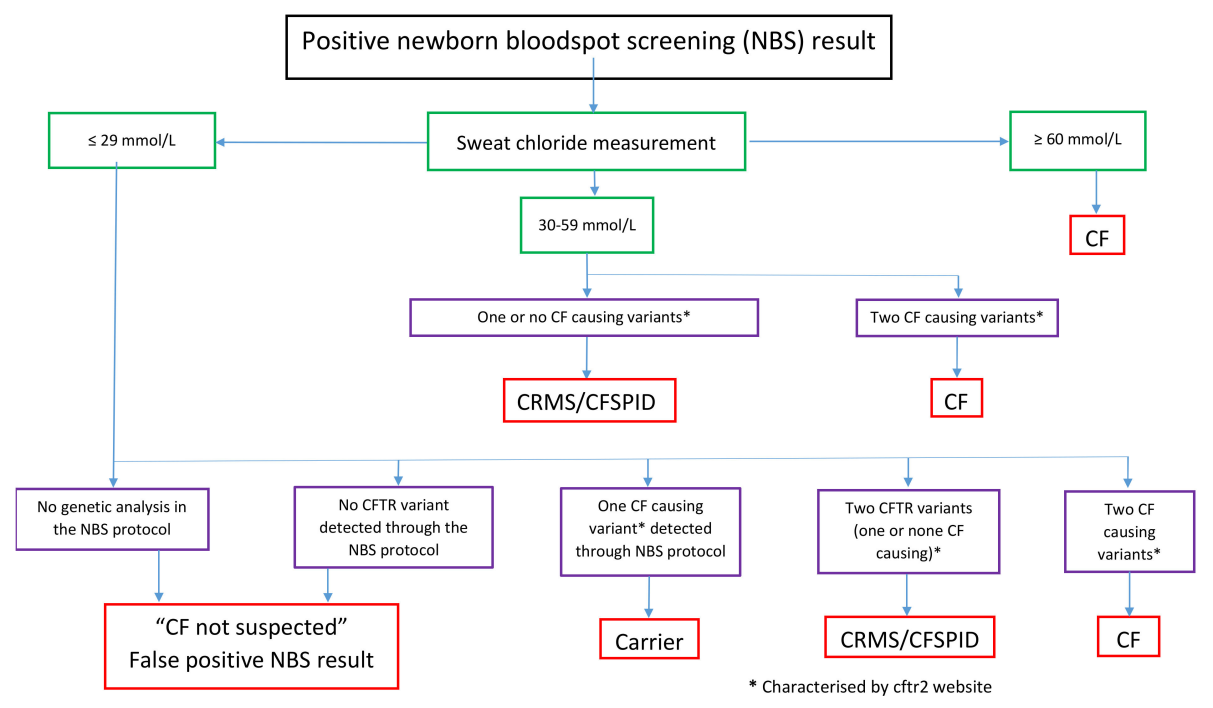

Figure 1. An algorithm for the designation of infants, following the positive newborn screening (NBS) result [9]. CF: Cystic fibrosis, CFTR: CF transmembrane conductance regulator (gene), CFMS: CFTR-related metabolic syndrome, CFSPID: CF screen-positive, inconclusive diagnosis.

\subsection{Incidence of CRMS/CFSPID across Europe}

Within the two past decades, there has been a huge increase in NBS programs for CF worldwide, including in Europe. A recent European survey [4] reported data from 16 out of the 17 national 
NBS protocols with centralized data collection. Since then, national programs have been developed in Portugal (2015), Germany (2016), Denmark (2016), Macedonia (2018) and Belgium (2020); and Spain and Italy have regional programs that provide extensive coverage of the population. Strategies of NBS protocols and structure of programs vary widely, like the proportion of cases designated CRMS/CFSPID, reflecting the different approaches. This survey collected data during the year 2014, when the definition of CFSPID was not yet available, and therefore the recognition of infants may possibly be underestimated. The ratio of infants with CF compared to CFSPID ranged from 1.2:1 (Poland) to 32:1 (Ireland), and protocols, including larger panels of DNA mutations, were more likely to identify those infants. Minimizing the number of cases with CRMS/CFSPID remains an important consideration in NBS programs, as referring and following these infants create a burden for their families and healthcare professionals, and the benefits remain unclear.

\subsection{Assessment of CFTR Protein Function}

In cases where repeated sweat tests' levels remain within the intermediate range, functional analyses measuring CFTR activity may help clarify the diagnosis. The assessment of the level of CFTR function is based on in vivo pharmacological studies, such as nasal potential difference (NPD) [11] or ex vivo intestinal current measurement (ICM) performed on rectal biopsies perfused in Ussing chambers [12], and on some occasion in combination with intestinal organoids analysis [13]. These evaluations of the CFTR function are performed exclusively in highly specialized CF centers and are not currently used in clinical practice. A diagnosis of CF can be ruled out when these functional analyses are within the normal range. The level of CFTR function further defines the likelihood of developing CF, as there is a continuum of CFTR dysfunction, and the paradigm of CF can be defined in terms of risk, depending on the severity of the dysfunction.

\section{Monitoring Infants Designated CRMS/CFSPID}

\subsection{Outcomes and Conversion to a Final Diagnosis of CF in Infants Designated CRMS/CFSPID}

Infants designated CRMS/CFSPID may later develop a diagnosis of CFTR-RD, and a number may have symptoms suggestive of $\mathrm{CF}$ and convert to a final diagnosis of $\mathrm{CF}$ (a less classical form in most cases). The range of conversion to CF varied widely in retrospective or registry database studies [14-18], from $6 \%$ [14] to $48 \%$ [15] (Table 2). Neither the definition of cases with an inconclusive diagnosis nor the diagnosis criteria for conversion to $\mathrm{CF}$ was consistent among these studies, as well as the duration of follow-up, thus providing an explanation in this wide range of conversion to CF. Reclassification to CF should be based either on subsequent positive sweat test and/or two CFTR variants as CF causing in trans according to new knowledge acquired in CFTR2. Conversion to CF is also more likely related to individual CFTR variants [19-21] and to infants with an initial intermediate sweat chloride (SC) value compared to normal SC [16]. In two recent prospective studies, the conversion rate varied from $11 \%$ [19] to $44 \%$ [21]. The first prospective study was set up by Ooi et al. [19] in eight CF centers in Canada and Italy. Eighty-two positive NBS infants with an inconclusive diagnosis of CF, born 2007-2013, were matched 1:1 with a cohort diagnosed with CF through NBS $(n=80)$ and were evaluated at a median age of 2.2 years. Those with a CRMS/CFSPID designation at baseline had significantly lower median IRT $(77 \mu \mathrm{g} / \mathrm{L}$ vs. $144 \mu \mathrm{g} / \mathrm{L}, p<0.0001)$ and SC values $(27.3 \mathrm{mmol} / \mathrm{L}$ vs. $83.2 \mathrm{mmol} / \mathrm{L}, p<0.0001$ ) compared to those diagnosed with CF. During follow-up, compared to those with $\mathrm{CF}$, they all had sustained exocrine pancreatic sufficiency and less respiratory symptoms as well as identification of Pseudomonas aeruginosa (12\% vs. 31\%) and Staphylococcus aureus ( $40 \%$ vs. $70 \%$ ). Among the 82 cases with a CRMS/CFSPID diagnosis, nine (11\%) children converted to a delayed CF diagnosis based on positive SC value $(n=2)$, with the identification of two CF-causing mutations in trans in the CFTR2 database at the time of data analysis $(n=4)$ or both in three cases. Serial repeated sweat testing showed a mean age of 21.3 months at the time of conversion in those diagnosed with CF with a positive SC value. Those who converted to CF had higher initial SC values, no clinical or 
anthropometric differences and a trend toward more Pseudomonas aeruginosa identification compared to those who did not convert to CF. Authors shed light on the limited duration of follow-up with a caution in interpretation, as manifestations suggestive of CF may not develop until adolescence or adulthood. The same team [22] analyzed a larger cohort with CRMS/CFSPID and found a difference in initial NBS IRT median values in those with delayed CF $(n=14)$ compared to those who remained CRMS/CFSPID $(n=83)$, respectively with a median [Q1-Q3] of 108.9 (72.3-126.8) vs. 73.7 (60.0-96.0); $p=0.02$, suggesting IRT initial value and trajectory over time as a potential tool to stratify young infants into high-risk or low-risk groups of developing CF. Munck et al. [21] reported a prospective multicenter study in France. Sixty-three positive NBS infants with an inconclusive diagnosis of CF, born 2002-2009, were matched 1:1 with a cohort diagnosed CF through NBS $(n=63)$ and evaluated at a mean age of 7.4 years. Those with a CRMS/CFSPID designation at baseline had a significantly lower median IRT $(97 \mu \mathrm{g} / \mathrm{L}$ vs. $166 \mu \mathrm{g} / \mathrm{L}, p<0.0001)$ and SC values $(40 \mathrm{mmol} / \mathrm{L}$ vs. $110 \mathrm{mmol} / \mathrm{L}, p<0.0001)$ compared to those diagnosed CF. During follow-up, compared to those with $\mathrm{CF}$, they all had sustained exocrine pancreatic sufficiency, less respiratory symptoms and identification of Pseudomonas aeruginosa (24\% vs. $82 \%$ ) and Staphylococcus aureus (68\% vs. 90\%). Among the 63 cases with a CRMS/CFSPID diagnosis, 28 (44\%) children converted to a delayed CF diagnosis based on a positive SC value $(n=8)$, with the identification of two CF-causing mutations in trans in the CFTR2 database at the time of data analysis $(n=12)$ or both in eight cases. All but six presented during follow-up respiratory symptoms suggestive of CF (productive cough, pathogens, antibiotic courses), although not specific to CF. Those who converted to CF had similar initial SC values, no clinical, anthropometric, respiratory pathogens, radiological or spirometry differences at final assessment compared to those who did not convert to $C F$. Infants recruited in these two studies reflected children currently diagnosed as CRMS/CFSPID, and the conversion to CF was defined by the above strict criteria. Explanations for the discrepancy in CF conversion rates among studies may be a time lag in infants' birth dates with differences in updated CFTR2 knowledge at the time of data analysis, as well as variations in the duration of follow-up.

\subsection{Management of Infants with CRMS/CFSPID Designation}

Whether screening newborns for CRMS/CFSPID is of clinical benefit has yet to be established, as most of these infants seem unlikely to develop any phenotype. Those designated CRMS/CFSPID have no clinical feature suggestive of CF at initial evaluation. It is important to provide accurate information to parents who feel psychologically distressed with the delivery of an initial positive NBS result and an inconclusive designation [23]. For an appropriate follow-up, most CF physicians agree that a balance is needed to avoid both overmedicalization and undertreatment, which can be a missed opportunity to prevent manifestations later in life. Nevertheless, there is no evidence that early proactive treatment leads to better long-term outcomes. Considering the US guidelines [5] published in 2009 and European recommendations [21,24] published in 2009 and updated in 2015 on early management, they are in agreement on care issues and on regular follow-up by a physician with an interest in CF encouraging clinical assessment rather than unnecessary explorations and including regular sweat testing. Clear information should be provided to the family and the primary care physician over time. Ooi et al. [19] considered his study as an interim one according to the short duration of monitoring and that CF-like manifestations may not develop until adolescence or adulthood. Data of Munck et al. [21], with a longer monitoring period and a more comprehensive respiratory status assessment, support a less intensive approach in the management of these infants compared to those with CF. They consider a possible discharge from the CF center after six years of age if the child has not converted to CF with the primary care physician remaining vigilant, especially for unexplained chronic lung disease. The best practice for monitoring these children is still an unanswered issue. Both prospective studies shed light on the need of further long-term prospective studies. In parallel, the ECFS NN WG is now working on a consensual document for monitoring these individuals from initial assessment to six years of age, with a diagnostic testing section, a care management section, including respiratory phenotype, and a review of evidence from a year-six assessment, with shared a decision on future care plans with the family. 
Table 2. Summary of recent studies of CRMS/CFSPID.

\begin{tabular}{|c|c|c|c|c|c|c|c|}
\hline & Kharrazi et al. [14] & Groves et al. [15] & Ren et al. [16] & Levy et al. [17] & $\begin{array}{c}\text { Terlizzi et al. } \\
\text { [18] }\end{array}$ & Ooi et al. [19] & Munck et al. [21] \\
\hline Study design & Retrospective & $\begin{array}{c}\text { Retrospective } \\
\text { case control }\end{array}$ & CFF registry & Cross sectional & Retrospective & $\begin{array}{l}\text { Prospective } \\
\text { case control }\end{array}$ & $\begin{array}{l}\text { Prospective } \\
\text { case control }\end{array}$ \\
\hline Country & USA California & Australia & US & US Wisconsin & Italy Tuscany & Canada, Italy & France \\
\hline Birth period & $2007-2012$ & $1996-2010$ & 2010-2012 & 1994-2012 & 2011-2016 & 2007-2013 & $2002-2009$ \\
\hline Follow up duration (y) & Mean 4.5 & 10 & 1 & 8 & Median 0.6 & Median 2.2 & Mean 7.4 \\
\hline Number CF & 345 & 225 & 1540 & 300 & 32 & 80 & 63 \\
\hline Number CRMS/CFSPID & 533 & $29^{2}$ & 309 & 57 & 50 & 82 & $63^{2}$ \\
\hline CF:CRMS/CFSPID & $0.65: 1$ & $7.8: 1$ & $5: 1$ & $5.2: 1$ & $0.64: 1$ & $1.8: 1^{6}$ & $6.3: 1^{6}$ \\
\hline Increased SCC $\geq 60 \mathrm{mmol} / \mathrm{L}$ & 17 & $2^{3}$ & & & 5 & 2 & 8 \\
\hline $2 \mathrm{CF}$ causing mutations & 0 & 0 & & & 0 & 4 & 12 \\
\hline Both criteria & 0 & 0 & & & 0 & 3 & 8 \\
\hline Other criteria & 3 & 12 & & & 0 & 0 & 0 \\
\hline Age at conversion $(y)$ & Mean $2.5 \pm 1.4$ & & & & Median $2(0.2-4)$ & Mean $1.8 \pm 1.2$ & Unk $^{1}$ \\
\hline Pseudomonas aeruginosa, N (\%) & Unk $^{1}$ & 78.6 & 10.7 & 39 & $25^{5}$ & 12 & 24 \\
\hline Pancreatic insufficiency, N (\%) & $3 / 15(15)$ & $4 / 29(14)$ & $14 / 309(4.5)$ & 0 & 0 & 0 & 0 \\
\hline F508del/R117H, N (\%) & Unk $^{1}$ & $4 / 14(29)$ & $80 / 309(26)$ & $37 / 57(63)$ & 0 & $16 / 82(19.5)$ & $27 / 63(43)$ \\
\hline
\end{tabular}

${ }^{1}$ Unk: unknown; ${ }^{2}$ definition slightly different from CRMS/CFSPID; ${ }^{3}$ only 8/14 had a repeated sweat test; ${ }^{4}$ NA: non-applicable; ${ }^{5}$ only $8 / 50$ had swab culture. CF: ${ }^{6}$ CF: CRMS/CFSPID ratio from the algorithm. Cystic fibrosis, CFTR: CF transmembrane conductance regulator (gene), CFMS: CFTR-related metabolic syndrome, CFSPID: CF screen-positive, inconclusive diagnosis, SCC: sweat chloride concentration 


\section{CRMS/CFSPID Registry Database}

Analysis of the 2010-2012 CFF Patient Registry database by Ren et al. [15] showed a high rate of misclassification of NBS-positive infants. On one hand, $11 \%$ of infants with CRMS had to be reclassified as $\mathrm{CF}$ after expansion of the number of CF-causing mutations and/or subsequent positive SC; and on the other hand, $41 \%$ of infants with CRMS were assigned as CF, despite not fulfilling the criteria. Now with the unified definition for infants designated CRMS/CFSPID, we can speculate that registry databases monitoring long-term outcomes will provide an accurate assessment of the risk of moving through adolescence or adulthood to CFTR-RD and CF diagnosis and will contribute to better define the modalities of monitoring. The ECFS NN WG is now working with the ECFS Registry team to prepare a European survey for infants with a designation of CRMS/CFSPID, aimed at recording the current situation of existing national or regional registries or databases, or plans and timelines to develop them.

Funding: This research received no external funding.

Acknowledgments: The author would like to thank K.W. Southern, Liverpool, UK, for his agreement to publish in the review Figure 1 and D. Delmas for her technical support.

Conflicts of Interest: The author declares no conflict of interest.

\section{References}

1. Dijk, F.N.; Fitzgerald, D.A. The impact of newborn screening and earlier intervention on the clinical course of cystic fibrosis. Paediatr. Respir. Rev. 2012, 13, 220-225. [CrossRef] [PubMed]

2. Yen, E.H.; Quinton, H.; Borowitz, D. Better nutritional status in early childhood is associated with improved clinical outcomes and survival in patients with cystic fibrosis. J. Pediatr. 2013, 162, 530-535. [CrossRef] [PubMed]

3. Tridello, G.; Castellani, C.; Meneghelli, I.; Tamanini, A.; Assael, B.M. Early diagnosis from newborn screening maximises survival in severe cystic fibrosis. ERJ Open Res. 2018, 4, 00109-2017. [CrossRef] [PubMed]

4. Barben, J.; Castellani, C.; Dankert-Roelse, J.; Gartner, S.; Kashirskaya, N.; Linnane, B.; Mayell, S.; Munck, A.; Sands, D.; Sommerburg, O.; et al. The expansion and performance of national newborn screening programmes for cystic fibrosis in Europe. J. Cyst. Fibros. 2017, 16, 207-213. [CrossRef]

5. Borowitz, D.; Parad, R.B.; Sharp, J.K.; Sabadosa, K.A.; Robinson, K.A.; Rock, M.J.; Farrell, P.M.; Sontag, M.K.; Rosenfeld, M.; Davis, S.D.; et al. Cystic Fibrosis Foundation practice guidelines for the management of infants with cystic fibrosis transmembrane conductance regulator-related metabolic syndrome during the first two years of life and beyond. J. Pediatr. 2009, 155 (Suppl. S6), S106-S116. [CrossRef]

6. Munck, A.; Mayell, S.J.; Winters, V.; Shawcross, A.; Derichs, N.; Parad, R.; Barben, J.; Southern, K.W. ECFS Neonatal Screening Working Group. Cystic Fibrosis Screen Positive, Inconclusive Diagnosis (CFSPID): A new designation and management recommendations for infants with an inconclusive diagnosis following newborn screening. J. Cyst. Fibros. 2015, 14, 706-713. [CrossRef]

7. Ren, C.L.; Borowitz, D.S.; Gonska, T.; Howenstine, M.S.; Levy, H.; Massie, J.; Milla, C.; Munck, A.; Southern, K.W. Cystic Fibrosis Transmembrane Conductance Regulator-Related Metabolic Syndrome and Cystic Fibrosis Screen Positive, Inconclusive Diagnosis. J. Pediatr. 2017, 181, S45-S51. [CrossRef]

8. Farrell, P.M.; White, T.B.; Ren, C.L.; Hempstead, S.E.; Accurso, F.; Derichs, N.; Howenstine, M.; McColley, S.A.; Rock, M.; Rosenfeld, M.; et al. Diagnosis of Cystic Fibrosis: Consensus Guidelines from the Cystic Fibrosis Foundation. J. Pediatr. 2017, 181, S4-S15. [CrossRef]

9. Southern, K.W.; Barben, J.; Gartner, S.; Munck, A.; Castellani, C.; Mayell, S.J.; Davies, J.C.; Winters, V.; Murphy, J.; Salinas, D.; et al. Inconclusive diagnosis after a positive newborn bloodspot screening result for cystic fibrosis; clarification of the harmonised international definition. J. Cyst. Fibros. 2019, 18, 778-780. [CrossRef]

10. Sosnay, P.R.; Salinas, D.B.; White, T.B.; Ren, C.L.; Farrell, P.M.; Raraigh, K.S.; Girodon, E.; Castellani, C. Applying Cystic Fibrosis Transmembrane Conductance Regulator Genetics and CFTR2 Data to Facilitate Diagnoses. J. Pediatr. 2017, 181, S27-S32. [CrossRef] 
11. Sermet-Gaudelus, I.; Girodon, E.; Roussel, D.; Deneuville, E.; Bui, S.; Huet, F.; Guillot, M.; Aboutaam, R.; Renouil, M.; Munck, A.; et al. Measurement of nasal potential difference in young children with an equivocal sweat test following newborn screening for cystic fibrosis. Thorax 2010, 65, 539-544. [CrossRef]

12. Derichs, N.; Sanz, J.; Von Kanel, T.; Stolpe, C.; Zapf, A.; Tümmler, B.; Gallati, S.; Ballmann, M. Intestinal current measurement for diagnostic classification of patients with questionable cystic fibrosis: Validation and reference data. Thorax 2010, 65, 594-599. [CrossRef] [PubMed]

13. De Winter-de Groot, K.M.; Berkers, G.; Marck-van der Wilt, R.E.P.; van der Meer, R.; Vonk, A.; Dekkers, J.F.; Geerdink, M.; Michel, S.; Kruisselbrink, E.; Vries, R.; et al. Forskolin-induced swelling of intestinal organoids correlates with disease severity in adults with cystic fibrosis and homozygous F508del mutations. J. Cyst. Fibros. 2019, in press. [CrossRef] [PubMed]

14. Kharrazi, M.; Yang, J.; Bishop, T.; Lessing, S.; Young, S.; Graham, S.; Pearl, M.; Chow, H.; Ho, T.; Currier, R.; et al. California Cystic Fibrosis Newborn Screening Consortium. Newborn Screening for Cystic Fibrosis in California. Pediatrics 2015, 136, 1062-1072. [CrossRef] [PubMed]

15. Groves, T.; Robinson, P.; Wiley, V.; Fitzgerald, D.A. Long-term outcomes of children with intermediate sweat chloride values in infancy. J. Pediatr. 2015, 166, 1469-1474. [CrossRef]

16. Ren, C.L.; Fink, A.K.; Petren, K.; Borowitz, D.S.; McColley, S.A.; Sanders, D.B.; Rosenfeld, M.; Marshall, B.C. Outcomes of infants with indeterminate diagnosis detected by cystic fibrosis newborn screening. Pediatrics 2015, 135, e1386-e1392. [CrossRef]

17. Levy, H.; Nugent, M.; Schneck, K.; Stachiw-Hietpas, D.; Laxova, A.; Lakser, O.; Rock, M.; Dahmer, M.K.; Biller, J.; Nasr, S.Z.; et al. Refining the continuum of CFTR-associated disorders in the era of newborn screening. Clin. Genet. 2016, 89, 539-549. [CrossRef]

18. Terlizzi, V.; Mergni, G.; Buzzetti, R.; Centrone, C.; Zavataro, L.; Braggion, C. Cystic fibrosis screen positive inconclusive diagnosis (CFSPID): Experience in Tuscany, Italy. J. Cyst. Fibros. 2019, 18, 484-490. [CrossRef]

19. Ooi, C.Y.; Castellani, C.; Keenan, K.; Avolio, J.; Volpi, S.; Boland, M.; Kovesi, T.; Bjornson, C.; Chilvers, M.A.; Morgan, L.; et al. Inconclusive diagnosis of cystic fibrosis after newborn screening. Pediatrics 2015, 135, e1377-e1385. [CrossRef]

20. Salinas, D.B.; Azen, C.; Young, S.; Keens, T.G.; Kharrazi, M.; Parad, R.B. Phenotypes of California CF Newborn Screen-Positive Children with CFTR 5T Allele by TG Repeat Length. Genet. Test. Mol. Biomark. 2016, 20, 496-503. [CrossRef]

21. Munck, A.; Bourmaud, A.; Bellon, G.; Picq, P.; Farrell, P.M.; DPAM Study Group. Phenotype of children with inconclusive cystic fibrosis diagnosis after newborn screening. Pediatr. Pulmonol. 2016, 20, 496-503. [CrossRef] [PubMed]

22. Ooi, C.Y.; Sutherland, R.; Castellani, C.; Keenan, K.; Boland, M.; Reisman, J.; Bjornson, C.; Chilvers, M.A.; van Wylick, R.; Kent, S.; et al. Immunoreactive trypsinogen levels in newborn screened infants with an inconclusive diagnosis of cystic fibrosis. BMC Pediatr. 2019, 19, 369. [CrossRef] [PubMed]

23. Hayeems, R.Z.; Miller, F.A.; Barg, C.J.; Bombard, Y.; Carroll, J.C.; Tam, K.; Kerr, E.; Chakraborty, P.; Potter, B.K.; Patton, S. Psychosocial Response to Uncertain Newborn Screening Results for Cystic Fibrosis. J. Pediatr. 2017, 184, 165-171. [CrossRef] [PubMed]

24. Mayell, S.J.; Munck, A.; Craig, J.V.; Sermet, I.; Brownlee, K.G.; Schwarz, M.J.; Castellani, C.; Southern, K.W. European Cystic Fibrosis Society Neonatal Screening Working Group. A European consensus for the evaluation and management of infants with an equivocal diagnosis following newborn screening for cystic fibrosis. J. Cyst. Fibros. 2009, 8, 71-78. [CrossRef]

(C) 2020 by the author. Licensee MDPI, Basel, Switzerland. This article is an open access article distributed under the terms and conditions of the Creative Commons Attribution (CC BY) license (http://creativecommons.org/licenses/by/4.0/). 